\title{
LOS “VERDADEROS AMIGOS” PARA LOS ESTUDIANTES HISPANOHABLANTES EN EL APRENDIZAJE DE LÉXICO ALEMÁN
}

\author{
Cristina Martínez Fraile \\ Universidad de Sevilla
}

\begin{abstract}
Resumen: El objetivo de este artículo es concienciar a los estudiantes hispanohablantes de que pueden desarrollar estrategias específicas para aprender léxico alemán. En este artículo proponemos que intenten reconocer en la lengua meta palabras parecidas en el plano de la expresión y en el plano del contenido a las ya conocen. En otros casos será necesario recurrir a estudios etimológicos realizados por investigadores para encontrar esos pares de palabras cuyos significados similares aparecen ocultos bajo su apariencia formal. Las palabras resultantes de este estudio contrastivo serán los "verdaderos amigos" para el estudiante.
\end{abstract}

Palabras clave: verdaderos amigos, transferencia, estudio contrastivo, constructivismo, etimología.

Abstract: The main objective of this paper is to educate the Spanish students that they may develop specific strategies to learn German words. These strategies are based on recognising in the target language words with a similar form and meaning to the words that the subject knows. The students sometimes should make a certain effort to learn irrecognizable words under slight disguises. The researchers could help to develop this strategy by providing an empirical and etymological study based on the two vocabularies. The similar words resulting from this contrastive study will be the "true friends" for the student.

Keywords: true friends, transfer, contrastive study, constructivism, etymology.

\section{INTRODUCCIÓN}

El término "verdaderos amigos"1 aplicado al aprendizaje de léxico de una lengua extranjera surge como una alternativa positiva frente al concepto de "falsos

1 Aprovechando la denominación de "falsos amigos" hay autores que, como Monserrat Fernández, también hace referencia a los "amigos reales" en M., Fernández, "La interacción negativa y positiva del inglés en el aprendizaje del alemán como L3: una propuesta de integración”, El alemán en su contexto español: actas IV congreso de la Federación de Asociaciones de Germanistas y profesores de Alemán en España, Santiago de Compostela, 26-28 de septiembre de 2002, Publicacións e 
amigos" o "falsos cognados". Si bien estos últimos se identifican con aquellas palabras que producen interferencias en el aprendizaje de léxico porque presentan similitudes con las palabras conocidas por el sujeto en el plano de la expresión pero no en el plano del contenido, los llamados "verdaderos amigos" son unidades léxicas afines tanto en la forma y como en el contenido (a las conocidas por el estudiante). Este factor contribuye a agilizar el proceso de aprendizaje del léxico de la nueva lengua.

Aunque encontrar los "verdaderos amigos" y los "falsos amigos" de una lengua sea el resultado de una práctica contrastiva realizada en ocasiones de forma inconsciente por el estudiante, también existen algunos estudios centrados en localizar preferentemente los "falsos amigos". Concretamente para los estudiantes alemanes hay un manual de "falsos amigos españoles" que es del que se han extraído la mayoría de los ejemplos que van a presentarse en este artículo.

En cambio, el estudio de los "verdaderos amigos" pasa desapercibido o no se le da la importancia que realmente tiene por no producir interferencias en el aprendizaje. No obstante, demostrar a los estudiantes que ya conocen muchas palabras de la nueva lengua sin sospecharlo es un beneficio y un recurso rentable que economiza su aprendizaje, sobre todo en los primeros niveles, pues contribuye a acrecentar la motivación cuando se enfrentan a un idioma totalmente desconocido para ellos.

Concretamente en este artículo se apuesta por un modelo de estudio contrastivo entre palabras alemanas y palabras españolas que, aún presentando distintos grados de similitud en el plano de la expresión, llegan a formar parte de una estrategia muy fructífera para asimilar su significado.

\section{EL ESTUDIO CONTRASTIVO ENTRE LENGUAS. UNA VISIÓN HISTÓRICA}

Del estudio contrastivo entre lenguas pueden extraerse aspectos aplicables a la didáctica de las lenguas extranjeras ${ }^{3}$.

Intercambio Científico, 2002, pp. 72-78.; Rusiecki se refiere a ellos como "Friends True"en J., Rusiecki, "Latent Bilingualism", Revista Papers and Studies in contrastive linguistics, 12 (1980), p. 82; Gerd Wotjak los define como "UL congruentes en la estructura semántica y también ampliamente en el plano de la expresión”. En G., Wotjak, Las lenguas, ventanas que dan al mundo: el léxico como encrucijada entre morfosintaxis y cognición: aspectos semánticos y pragmáticos en perspectiva intra e interlingüistica, Salamanca, Ediciones Universidad de Salamanca, 2006.

2 D., Ludwig, Sprachfallen. Spanisch, München, Max Hueber Verlag, 2001.

3 Die Kontrastive Linguistik beschäftigt sich aus synchroner Sicht mit Unterschieden und Übereinstimmungen zwischen zwei oder mehreren Sprachen (vgl. Beerbom 1992: 83).(...) Sie verfolgt insbesondere zwei Ziele: sie will einerseits universale und sprachtypologische Aspekte aufzeigen und andererseits didaktische Aspekte für den Fremdsprachenunterricht erfassen. Damit nimmt die Kontrastive Linguistik eine Zwischenstellung zwischen Theoretischer und Angewandter Sprachwissenschaft ein. Ihr Status, insbesondere die Abgrenzung zu benachbarten sprachwissenschaftlichen Teildisziplinen, ist nicht abschließend geklärt. Allerdings spricht ihre zunehmend praktische Orientierung, die sowohl dem Fremdsprachenunterricht als auch dem 
Aunque determinadas tendencias como el enfoque minimalista y el método comunicativo prefirieron descartar el estudio contrastivo en el aprendizaje de lenguas extranjeras, este procedimiento se viene defendiendo desde hace más de dos siglos. El enfoque minimalista pretendía restringir al mínimo la influencia de la L1 del aprendiz en la adquisición de una L2. En su propuesta descartaban los primeros resultados procedentes de la teoría contrastiva, pues, según ellos el enfoque contrastivo explicaba el aprendizaje de una lengua extranjera en función de la influencia positiva o negativa de la lengua materna. Heredero del enfoque minimalista, el método comunicativo (kommunikative Didaktik), que surge en los años setenta, proponía el uso exclusivo de la lengua extranjera en el aula.

Hasta finales de los años ochenta y principios de los años noventa los llamados métodos directos o comunicativos todavía consideraban que el contacto entre lenguas conducía únicamente a confusión y a error.

Anterior a estas posturas, en 1906, investigadores como Schuyten y Netschajeff realizan los primeros estudios basados en el empleo de estrategias contrastivas que toman como referencia la lengua materna para entender el significado de algunas palabras extranjeras:

SCHUYTEN (1906) folgerte aus ihren Experimenten mit parallelen Reihen von Wortpaaren, daß die Verwendung des muttersprachlichen Wortes als Stimulus dann am lerneffektivsten ist, wenn die Wörter auch durch diesen Stimulus abgefragt werden, daß im umgekehrten Fall aber der fremdsprachliche Stimulus günstiger ist. Diese Festellung wurde durch NETSCHAJEFF (1908) bestätigt ${ }^{4}$.

Del mismo modo Netschajeff confirma la postura de Schuyten a partir de sus experimentos:

Alle Daten unserer Versuche zeigen, daß das unbekannte Zungenmaterial am besten angeeignet wird, wenn es mit den Elementen der Muttersprache in Assoziation tritt. Mit anderen Worten ist es unvorteilhaft, die Muttersprache eines Individuums unberücksichtigt zu lassen, wenn man es eine fremde Sprache lehrt ${ }^{5}$.

A mediados del siglo XX la lexicología contrastiva parte de modelos fundamentales de investigación ${ }^{6}$ entre los que cabe destacar el de Robert Lado por

Übersetzen und der Übersetzerausbildung zugute kommt, dafür, sie der Angewandten Sprachwissenschaft zuzuordnen. En R., Arntz, Studien zur Sprache und Technik. Hildesheim, Georg Olms Verlag, 2001, p.21

${ }^{4}$ En. K., Macht, / F., Steiner, Erfolgsfaktoren des Vokabellernens, Augsburg, Universität Augsburg, 1983, p.14

5 Ibíd.; p. 15

6 Ver otros modelos como el de Stockwell, Bowen, Martín (1965); Coseriu (1977); Di Pietro (1971); Martín Mingorance (1984). Entre los citados hemos toma el de Lado como el más 
su clara orientación pedagógica frente a otros modelos contrastivos más teóricos. En su obra Lingüistica contrastiva. Lenguas y culturas ${ }^{7}$, dedicó el capítulo IV a proponer una metodología para la comparación de los léxicos de distintas lenguas. En él afirmaba que las palabras de la lengua extranjera que se parecen a las de la lengua materna resultarían fáciles y, por el contrario las que fuesen distintas resultarían difíciles.

Ya a finales del siglo XX y principios de este siglo aparece una gran cantidad de proyectos entre los que cabe destacar EuroComRom. Die sieben Siebe $e^{8}$ (Horst G. Klein y Tilbert D. Stegmann, 1999), Deutsch nach Englisch ${ }^{9}$ (Hufeisen, 2003) y Polnisch via Russich ${ }^{10}$ (Weller, 2001) junto a otros trabajos como Probleme des Wortschatzsarbeit ${ }^{11}$ (Bohn, 2000) y How to study foreign language ${ }^{12}$ (Lewis, 1999), que categorizan la transferencia de palabras conocidas como un recurso muy eficaz y positivo en el aprendizaje de léxico de una nueva lengua.

También el constructivismo, como teoría del conocimiento, insiste en la necesidad de analizar los conocimientos previos y la experiencia anterior del estudiante (como por ejemplo su lengua materna o el conocimiento de otras lenguas) antes de introducir contenidos nuevos. ${ }^{13}$ "Je zuttreffender und genauer man weiß, wie dasjenige ist, was der Lernende hat und dasjenige, das er zu $h a-$ ben sucht, desto leichter wird es sein, ihm zu helfen.” (Cartegena / Gauger, 1989: $400)^{14}$.

representativo para esta investigación pues es de los que tiene una clara aplicación para el aprendizaje de lenguas; los demás, en cambio, prescinden de la orientación pedagógica y se centran en determinar estructuras universales de las lenguas contrastadas. Cfr. J. M., Martín, "Lexicología contrastiva: principios, orientaciones, métodos.” en J., Luque, / A., Bertrán, Segundas jornadas sobre estudio y enseñanza del léxico. Granada: Método Ediciones, 1996, pp. 24-27.

7 R., Lado, Lingüística contrastiva. Lenguas y culturas. Traducción de Joseph A. Fernández, Madrid, Ediciones Alcalá, 1957..

8 Con este juego de palabras Die sieben Siebe los autores analizan el proceso de aprendizaje de nuevas lenguas extranjeras y proponen siete ámbitos en los que pueden hallarse analogías entre las lenguas procedentes de una misma familia lingüística. Estos recursos podrían definirse como los siete filones de conocimientos afines en todas las lenguas:primer recurso: el vocabulario internacional; segundo recurso: el vocabulario panrománico; tercer recurso: correspondencias fonéticas; cuarto recurso: grafía y pronunciaciones; quinto recurso: frases básicas; sexto recurso: morfosintaxis; séptimo recurso: prefijos y sufijos. En H., Klein, / T., Stegmann, EuroComRom. Die sieben Siebe. Aachen, Shaker, 1999.

9 B., Hufeisen, / G., Neuner, Mehrsprachigskeitskonzept: Tertiärsprachenlernen - Deutsch nach Englisch. Europarat, Goethe Institut, 2003

10 O., Weller, Polnisch via Russisch verstehen. Slavische Interkomprehension im Rahmen der EuroCom-Strategie. Bielefeld, Universität Bielefeld, 2001

11 R., Bohn, Probleme der Wortschatzarbeit, Kassel, DIFF/Goethe Institut, 2000

12 M., Lewis, How to study foreign languages, New York, Palgrave, 1999

13 En este sentido coincidía con el enfoque contrastivo que considera esencial este primer paso en el proceso de aprendizaje para determinar lo que el estudiante ya sabe de la nueva lengua.

14 N., Cartegena / H.M., Gauger, Vergleichende Grammatik Spanisch-Deutsch. 2 Bände, Mannheim, Dudenverlag, 1989. 
El constructivismo le dedica una especial atención a la enseñanza de lenguas extranjeras y, a propósito del aprendizaje de lenguas, Dieter Wolff en su obra Fremdsprachenlernen als Konstruktion ${ }^{15}$ recoge las bases ideológicas, los principios y las consecuencias de una aplicación del constructivismo en la didáctica de las lenguas extranjeras. Manifiesta que en la construcción y en el aprendizaje de una lengua nueva el sujeto adquiere un idioma sobre las experiencias y los conocimientos previos de su propia lengua y de otras lenguas aprendidas. El mismo alumno, casi de manera instintiva, tiende a relacionar y a contrastar los conceptos ya adquiridos con aquellos nuevos que va a aprender. Esta destreza se conoce en la enseñanza de lenguas extranjeras con el nombre de "transferencia" y "tiene lugar cuando el estudiante de una L2 hace uso de su conocimiento lingüístico y habilidades comunicativas previas (sean las de su lengua materna o las de cualquier otra lengua que conozca) a la hora de hacerse con nuevo conocimiento sobre la L2, al producir o procesar mensajes en dicha lengua." (Manchón 2001: $40)^{16}$

Según el grado de conciencia que se tenga a la hora de emplear estos recursos también se diferencia entre destreza y estrategia. Por ejemplo, adivinar intuitivamente el significado de una palabra es una destreza que utilizada intencionadamente cuando sea preciso se convierte en una estrategia. Generalmente se habla de estrategias utilizadas de forma inconsciente (destreza) y consciente (estrategia). (Manchón 2001: 153)

\section{LA ETIMOLOGÍA: UN RECURSO DEL INVESTIGADOR PARA LOCA- LIZAR PARES DE PALABRAS SIMILARES EN ALEMÁN Y EN ESPAÑOL}

Vamos a analizar el sistema contrastivo formulado por Robert Lado del que parte nuestro proyecto. No obstante, el presente trabajo aporta además un nuevo criterio que se puede aplicar al ejercicio contrastivo que este autor planteaba para aprender el léxico de una lengua extranjera. Su propuesta se basaba en pronunciar las palabras extranjeras para determinar en qué medida eran similares a las palabras de la lengua nativa. De este modo, establecía una primera clasificación agrupando las palabras extranjeras que presentaban similitudes formales con las palabras de la lengua materna, descartando las otras.

15 D.,Wolff, Fremdsprachenlernen als Konstruktion: Grundlagen für eine konstruktivistische Fremdsprachendidaktik, Frankfurt am Main, Peter Lang, 2002.

$\mathrm{Se}$ trata de una un marco metodológico sobre el aprendizaje de lenguas tomado como referente teórico-psicolingüístico porque nutre la metodología contrastiva aplicada al aprendizaje del léxico.

16 R. M., Manchón, "Un acercamiento psicolingüístico al fenómeno de la transferencia en el aprendizaje y el uso de segundas lenguas", AA.VV. Estudios de Lingüística. Tendencias y líneas de investigación en adquisición de segundas lenguas. Alicante, Universidad de Alicante, 2001, pp. $37-155$. 
Según Lado, el criterio para discernir entre lo semejante y lo diferente, margen que calificaba de "borroso", quedaba en manos de la persona que hacía la comparación. Describía de esta forma el proceso que el sujeto lleva a cabo en su análisis contrastivo:

puede repasar la selección de vocabulario en una lengua extranjera, pronunciando cada palabra en voz alta. Rápidamente puede decidir si se parece o no a una palabra de la lengua nativa. Cada palabra que se parezca hay que ponerla aparte, si está en una ficha, o hay que apuntarla en una hoja o en una ficha. Según se vayan descubriendo relaciones de semejanza, estas palabras parecidas pueden clasificarse en grupos. (Lado 1957: 96)

$\mathrm{El}$ autor dio un gran paso al tomar como referencia la lengua nativa del sujeto que compara, ya que este criterio contaba con la experiencia lingüística personal. Nuestra propuesta va más allá de la propia pronunciación del alumno en tanto que intentamos ampliar su léxico presentándole las correspondencias de las que no se haya podido percatar. Para ello sería necesario utilizar otro método complementario como es el de la etimología. De este modo, se ofrecerían nuevas asociaciones entre las palabras alemanas y otras palabras conocidas por el estudiante, procedentes de su lengua materna o de otras lenguas. De entre las correspondencias etimológicas propuestas el estudiante decidiría cuáles le resultarían útiles y significativas.

Consideramos que no es trabajo del investigador tomar la pronunciación como única referencia para discernir entre las palabras parecidas o diferentes en su forma, pues se trata de una tarea propia del sujeto que aprende la lengua extranjera. Para complementar esta estrategia el investigador puede valerse de otro criterio más objetivo como la etimología, precisamente el recurso que hemos tomado como referencia en el ejemplo que vamos a proponer más adelante. Para ello nos apoyamos en las afirmaciones de Gerd Wotjak:

Sólo a partir de la "biografía de la palabra", de la búsqueda cuidadosa de los orígenes, surgiría la imagen informativa y compleja del desarrollo de cierta ULa. Posiblemente, la instantánea global sincrónica permite ciertas conclusiones en dirección a la elaboración de recomendaciones (preferencias, tendencias) para adaptaciones grafemático-fonéticas y morfológicas para las ULa respectivas. Con ello también se obtienen informaciones útiles para la adquisición de una lengua extranjera. Que hay que abordar las clasificaciones con sumo cuidado, se da por sobreentendido (Wotjak 2006: 332).

El uso de la etimología resulta aquí significativo para comparar y asociar palabras de distintas lenguas a partir de sus raíces. De esta forma, frente a la pronunciación, como criterio discriminatorio y subjetivo, la etimología se presenta como un recurso descriptivo y objetivo que ofrece otras posibles combinaciones. Contemplamos la idea de que el análisis etimológico de las palabras extranjeras 
puede aportar otros parecidos que no se evidencian con sólo pronunciar las palabras. En este sentido, las relaciones etimológicas constituyen un campo de investigación con el que se contribuiría a crear un grupo de "palabras similares alemanas y españolas" contando, esta vez, con otro fundamento que puede asegurar que haya, además de una correspondencia en el plano de la expresión, una congruencia en el plano semántico si se cuenta con una misma raíz.

El análisis etimológico permite revelar la presencia de préstamos o de palabras heredadas de una misma lengua fuente común al español y al alemán. Pero cuando más provecho se puede sacar de este recurso es precisamente cuando las similitudes permanecen semiocultas en alemán bajo su apariencia formal. De esta forma, se elaborará un grupo formado por "palabras alemanas transparentes" y otro formado por "palabras alemanas traslúcidas". Esta denominación es nuestra y, aunque es propia del sentido visual, su aplicación viene motivada porque, como su nombre indica, el significado de las "palabras alemanas transparentes" queda muy claro y evidente para el estudiante hispanohablante por el parecido que presenta con las palabras de su lengua. Die Bar, die Banane o die Marmelade, entre otras, son ejemplos de "palabras alemanas transparentes". Encontrar palabras "transparentes" en alemán es posible cuando las palabras alemanas proceden en su mayoría de las lenguas clásicas, de las lenguas románicas y/o cuando se trata de préstamos alemanes o germanos en español y viceversa.

Cuando las similitudes entre las palabras alemanas y las palabras españolas aparecen semiocultas, las denominamos "palabras alemanas traslúcidas" porque agrupan pares de palabras en los que se pueden evidenciar una afinidad en el plano de la expresión, y por supuesto en el plano del contenido, pero solamente perceptible tras un análisis etimológico. Del mismo modo, la denominación de "palabras alemanas traslúcidas" es nuestra. Sobre ellas se centra fundamentalmente nuestro trabajo etimológico, siendo la etimología la herramienta que hemos utilizado para eliminar los restos que la historia de la lengua ha ido dejando en estas palabras procedentes en su origen de una misma raíz.

\section{UN CASO PRÁCTICO: ASOCIANDO PALABRAS REFERIDAS AL CAMPO SEMÁNTICO DE LA ALIMENTACIÓN. (VÉASE EL ANEXO)}

Para ilustrar la estrategia que proponemos hemos seleccionado en este artículo sólo una muestra de cien ejemplos referidos al campo semántico de la alimentación.

Casi todos los libros de texto incluyen unidades didácticas que abordan el tema de los alimentos y de la restauración en general. La mayor parte de los manuales de enseñanza de segundas lenguas contiene una primera página de inmersión sobre el tema que se va a tratar. Su función consiste no sólo en introducir la nueva materia sino en analizar los conocimientos previos del alumno. Pensamos que en el apartado dedicado al léxico sería útil mostrar al alumno algunas similitudes que comparten las nuevas palabras que va a aprender y 
aquellas que ya conoce (procedentes tanto de su lengua materna como de otras segundas lenguas).

Una primera actividad consistiría en presentarles un compendio de palabras en el que el estudiante tuviese que rodear sólo de forma lúdica aquellas que cree reconocer.

(La información que sigue a cada palabra es su genitivo y su plural, ambas separadas por una barra quedando de esta forma: artículo palabra genitivo/plural)

die Aprikose -/n backen

die Banane /n die Bar -/s das Becken s/das Spülbecken beißen

das Bier es/e die Birne /n ein bisschen der Bonbon s/s brennen verbrennen a-a das Brot es/e die Butter das Café s/s der Chef s/s der Durst es das Dutzend s/e das Feuer s/das Feuerzeug die Feuerwehr der Fisch frieren frisch gefrieren die Frucht /ü-e füttern die Gabel/n das Gemüse s/das Glas es/ä-er der Gramm s/der Gummi s/s der Imbiss es, e der Kaffee s die Kaffeemachine der Kakao s

kalt

die Kälte

sich erkälten

die Erkältung

die Karotte $-/ \mathrm{n}$

die Kartoffel/n

der Käse s/-

der Ketchup

das Kilogramm s/-

die Kirsche /n

kochen

die Küche /n

der Kuchen s/-

kühl

lecker

der Likör

das/der Liter s/-

der Löffel s/-

die Majonäse -/n

der Markt es/ä-e

die Marmelade

das Mehl s/e

das Menü s/s

die Milch

mild

mischen

das Mü(e)sli

die Nuss -/Nüsse

das Ö1 s/e

die Orange - orange

die Pizza -/s die Pommes(frites)

probieren

die Qualität/en

die Quantität /en

das Restaurant s/s

roh

der Saft s/ä

das Salz es/e

das Sandwich es/e

satt sein

schälen

die Spaguetti

die Speise /n

die Nachspeise

der Supermarkt

die Suppe /n

süß

die Tasse /n

der Tee s/Teesorten

der Teller s/-

die Tomate -/n

trinken

das Getränk s/e

warm /wärmer /

die Wärme

das Wasser s/-

das Trinkwasser

der Wein es/e

die Zitrone -/n

der Zucker 
(Esta muestra ha sido recogida del léxico básico alemán de más de tres mil palabras presentado por el Marco Común Europeo en la obra Profile Deutsch ${ }^{17}$.)

Es muy probable que el alumno rodee aquellas palabras que durante nuestro trabajo hemos calificado de "palabras alemanas transparentes". Son aquellas que hemos resaltado en negrita. Habrá otros alumnos que, valiéndose de sus conocimientos de otras segundas lenguas, tal vez rodeen algunas más. Por ejemplo, estableciendo vínculos con el inglés podrían señalar las siguientes palabras:

\section{die Butter - butter, das Ö1 - oil, der Fisch - fish, trinken - to drink, das Glas - glass, das Wasser- water, die Milch - milk, der Wein - wine, die Orange - orange}

De esta forma se va reduciendo el número de palabras desconocidas para el alumno, tanto que, de las cerca de cien palabras nuevas ya conoce un cuarenta por ciento.

Acto seguido, el profesor debe presentar a los alumnos determinadas estrategias para recordar el significado de aquellas palabras que les resultan totalmente desconocidas y puede hacerlo estableciendo vínculos con otras palabras que conocen, resaltando su parecido a partir de algunas pinceladas etimológicas. En principio las palabras desconocidas para el estudiante serían todas excepto señaladas en negrita en el primer listado.

De todas estas entradas vamos a ilustrar cómo podría enseñarse al alumno a realizar el ejercicio de transferencia sólo con algunas palabras. El resto se presentará en el anexo.

Ante la palabra alemana das Brot posiblemente el alumno se encuentre desorientado y pase por alto determinadas similitudes entre Brot y algunas de las palabras que él conoce. Será el profesor, como mediador, quien dirigirá y ayudará al alumno en el proceso de comprensión y asimilación de la palabra extranjera. Éste le indicará la palabra española que puede ejercer de vínculo para deducir el significado de la nueva palabra alemana, vínculo que a su vez favorecerá la memorización.

El profesor, si conoce la evolución etimológica de la palabra alemana Brot, puede instruir al alumno sugiriéndole que relacione Brot con la palabra española brotar.

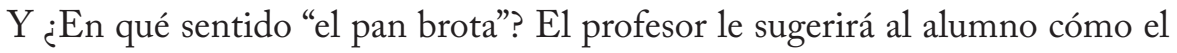
pan en su proceso de fermentación con la levadura hace como si brotase.

Esta relación que el profesor establece entre Brot y brotar para que el alumno mnemotécnicamente recuerde lo que significa pan está basada precisamente en

17 M., Glaboniat, / M., Müller, Profile Deutsch. Gemeinsamer europäische Referenzrabmen, Berlín, Langenscheidt, 2005. 
la etimología de la palabra. Las dos palabras proceden de la misma raíz indoeuropea bher-.

\begin{tabular}{|c|c|c|c|}
\hline $\begin{array}{l}\text { PALABRA } \\
\text { ALEMANA } \\
\text { das Brot es/e }\end{array}$ & $\begin{array}{l}\text { ETIMOLOGÍA } \\
\text { Relacionada con bramen > re- } \\
\text { lac. bärme < idg. bher(e)-, < } \\
\text { bhreu- hervir, quemar > lat. } \\
\text { fermentum > fermento } \\
\text { esp. brotar < brotar < gót. } \\
\text { brŭt; cfr. a. al. ant. broz< } \\
\text { brot|zeln: brutzeln > brodeln } \\
<\text { idg. bher- }\end{array}$ & $\begin{array}{l}\text { VÍNCULO } \\
\text { brotar (el pan } \\
\text { en el momento } \\
\text { de fermentar } \\
\text { parece como } \\
\text { si estuviese } \\
\text { brotando) }\end{array}$ & $\begin{array}{l}\text { PALABRA } \\
\text { ESPAÑOLA } \\
\text { el pan }\end{array}$ \\
\hline
\end{tabular}

¿Cómo relacionaríamos kochen con cocer, cocinar?

En este caso resultaría muy simple. Le enseñaríamos al alumno a cambiar ciertas letras de kochen. Las dos letras marcadas en negrita se podrían cambiar por una c, de tal forma que obtendríamos la palabra *cocen y de aquí cocer. Muy próxima a la acción de cocer, mediante la asociación de ideas, llegaríamos también hasta cocinar.

Nuevamente la relación de estas tres palabras está basada en el origen etimológico que comparten:

\begin{tabular}{|l|l|l|l|}
\hline $\begin{array}{l}\text { PALABRA } \\
\text { ALEMANA } \\
\text { kochen }\end{array}$ & ETIMOLOGÍA & VÍNCULO & $\begin{array}{l}\text { PALABRA } \\
\text { ESPAÑOLA } \\
\text { cocer, cocinar }\end{array}$ \\
$\begin{array}{l}\text { <lat. coquere (lat. cocere) } \\
\text { esp. cocer < lat. coquere } \\
\text { esp. cocinar < lat. coquinare } \\
\text { lat. coquere }\end{array}$ & cocer & \\
\hline
\end{tabular}

¿En qué se parecen Kirsche y cereza? A simple vista no se asemejarían en nada. No obstante, la etimología nos revela que las dos palabras proceden del latín ceresia.

Después de haber realizado el estudio de más de tres mil palabras y del que sólo hemos presentado aquí una selección, llegamos a la conclusión de que la mayoría de las palabras que empiezan con $\mathbf{K}$ en alemán proceden del latín y se corresponden con palabras españolas que comienzan con $\mathbf{C}$, que a su vez proceden de la misma etimología latina. Por ello, sería factible recomendar tendencias para realizar posibles adaptaciones grafemático-fonéticas y morfológicas entre las palabras alemanas y españolas. ${ }^{18}$

18 Cfr. Wotjak 2006: 332 
Del mismo modo la $\mathbf{C H}$ en las palabras alemanas de origen latino se corresponden en español con una C. De esta forma, aplicamos el cambio en la palabra alemana Kirsche:

Kirsche $>{ }^{*}$ circe $>{ }^{*}$ cirice $>$ cereza

\begin{tabular}{|c|c|c|c|}
\hline $\begin{array}{l}\text { PALABRA } \\
\text { ALEMANA } \\
\text { die Kirsche } \\
\text { /n }\end{array}$ & $\begin{array}{l}\text { ETIMOLOGÍA } \\
\text { < lat. ceresia < lat. cerasus < } \\
\text { lat. ceresia griech. kérasos } \\
\text { esp. cereza < lat. cereš̆a < lat. } \\
\text { cerasĭum < gr. kepásos }\end{array}$ & $\begin{array}{l}\text { VÍNCULO } \\
\text { cereza }\end{array}$ & $\begin{array}{l}\text { PALABRA } \\
\text { ESPAÑOLA } \\
\text { la cereza }\end{array}$ \\
\hline
\end{tabular}

Estas diferencias en la grafía de cada lengua son consecuencia de la distinta evolución fonética. Por este motivo, además de la información etimológica es necesario aclarar las mínimas diferencias entre las palabras investigadas.

Finalizamos esta ilustración con un último ejemplo como es el caso de la palabra alemana satt. En muchas ocasiones el alumno se acuerda del significado de una palabra porque empieza igual que otra que él conoce. Por ejemplo satt y satisfecho comienzan de la misma forma y el hecho no es casual. Nuevamente la etimología nos informa que las dos palabras proceden de la misma raíz indoeuropea:

\begin{tabular}{|l|l|l|l|}
\hline $\begin{array}{l}\text { PALABRA } \\
\text { ALEMANA } \\
\text { satt sein }\end{array}$ & $\begin{array}{l}\text { ETIMOLOGÍA } \\
\text { VínCULO sa-, se- } \\
\text { esp. saciar, saciedad, satisfacer } \\
\text { < lat. satiāre < idg. sa-, se- } \\
\text { esp. saturar < lat. saturāre } \\
\text { idg. sa-, se- }\end{array}$ & $\begin{array}{l}\text { PALABRA } \\
\text { ESPANiar, sacie- } \\
\text { dad, satisfacer, } \\
\text { saturar }\end{array}$ & $\begin{array}{l}\text { estar satisfecho } \\
\end{array}$ \\
\hline
\end{tabular}

Como se ha podido comprobar se pueden ofrecer breves datos etimológicos sin llegar a aburrir al alumno. Su función es meramente informativa y en ningún caso tendría que aprenderlos. Es un material que resulta más útil al profesor, que actúa como mediador, que al alumno ${ }^{19}$; y porque es muy posible que el estudiante solo y sin ayuda no llegue a establecer esta relación, la figura del profesor es importante sobre todo al principio del proceso constructivo de la lengua nueva.

La última fase de este ejercicio sobre el vocabulario aparecería en la última página de cada lección. Es habitual que los manuales presenten también una

19 Con la excepción del alumno autodidacta a quien sí le serviría tener esta información etimológica presente. 
página de revisión del tema que se ha trabajado. Sería el momento de volver a mostrar al alumno todo el léxico de la lección y de invitarle a que rodease de nuevo las palabras que ya conoce. De este modo, constataremos que la información etimológica de la palabra ha sido útil para deducir el significado de la palabra desconocida y que esta vez el número de palabras rodeadas y conocidas ha crecido.

Esta es una práctica que puede aportar resultados muy satisfactorios tanto para el profesor como para el alumno. Por una parte, el profesor halla en ella una forma de motivar al alumno y de presentarle el aprendizaje de vocabulario de forma lúdica y entretenida, dejando a un lado el hecho de tener que proponer la tediosa tarea del estudio meramente memorístico. Por otra parte, el alumno afrontará el aprendizaje del vocabulario como un juego y desaparecerá en él la sensación de enfrentarse a una lengua totalmente desconocida si desde un primer momento se siente vinculado de alguna forma con la nueva lengua sabiendo que ya conoce mucho de lo que tiene que aprender.

Un anexo que se presentará en este artículo ofrece tanto al profesor como al alumno información etimológica útil a la hora de buscar esos vínculos entre las palabras alemanas desconocidas y palabras españolas.

La presentación se realiza mediante una tabla para que el estudiante pueda advertir las similitudes entre las palabras alemanas y las palabras españolas y la forma de vincularlas de una sola ojeada.

*Se ofrece también el género de la palabra alemana mediante su artículo correspondiente, así como su genitivo y su plural (gen./pl.)

\begin{tabular}{|l|l|l|l|}
\hline $\begin{array}{l}\text { PALABRA } \\
\text { ALEMANA }\end{array}$ & ETIMOLOGÍA & VÍNCULO & $\begin{array}{l}\text { PALABRA } \\
\text { ESPAÑOLA }\end{array}$ \\
\hline das Brot es/e & $\begin{array}{l}\text { < idg. bher(e)-, < bhreu- her- } \\
\text { vir, quemar > lat. fermentum > } \\
\text { fermento } \\
\text { esp. brotar < brotar < gót. } \\
\text { brŭt; cfr. a. al. ant. broz< } \\
\text { brot|zeln: brutzeln > brodeln } \\
<\text { idg. bher- }\end{array}$ & $\begin{array}{l}\text { brotar (el pan } \\
\text { en el momento } \\
\text { de fermentar } \\
\text { parece como } \\
\text { si estuviese } \\
\text { brotando) }\end{array}$ & el pan \\
\hline $\begin{array}{l}\text { die Frucht } \\
\text { /ü-e }\end{array}$ & $\begin{array}{l}<\text { lat. fructus } \\
\text { esp. fruto < lat. fructus }\end{array}$ & fruto, fruta & la fruta \\
\hline
\end{tabular}

Asimismo el estudio contrastivo de pares de palabras alemanas y españolas permite detectar algunos posibles "falsos amigos". En esos casos debe llamarse la atención sobre ellos aunque la forma de presentárselos al alumno difiere mucho 
de cómo se ha venido haciendo hasta ahora y para ello nos basamos en la siguiente idea:

No deja de resultar curioso como la etimología pone al descubierto que mayoría de los "falsos amigos" guardan una relación semántica entre sí. En la selección presentada en este artículo aparecen los falsos amigos Bonbon (al.) y bombón (esp.). Existen dos semas que estos dos términos comparten: los dos son golosinas y las dos palabras proceden de una misma raíz francesa bonbon.

Otros ejemplos, aunque no referidos al campo semántico de la alimentación pero que sirven para ilustrar la relación semántica que los "falsos amigos" guardan entre sí, serían las palabras al. Mappe (carpeta) - esp. Mapa y los "falsos amigos" al. mantel (abrigo) - esp. mantel.

Aquí la etimología juega un papel relevante pues desvela que los considerados "falsos amigos" como Mappe y Mapa o Mantel y mantel en sus orígenes derivaron de una misma raíz a partir de la que se podría explicar la relación semántica que comparten.

al. Mantel (abrigo) < lat. mantellum

esp. mantel (cubremesa) < lat. mantēle $<$ lat. mantellum

Lo mismo pasa con las palabras Mappe y mapa.

al. Mappe (carpeta; originariamente carpeta para guardar los mapas) < lat. mappa mundi < lat. mappa

esp. mapa $<$ lat. mappa mundi < lat. mappa

De esta forma, en vez de destacar las diferencias y de presentar las palabras Mappe y mapa o Mantel y mantel como simples "falsos amigos" se podría resaltar la pasada identidad común de estos vocablos, siempre advirtiendo al estudiante que se muestre en alerta cuando encuentre estas palabras y que reflexione sobre la asociación. Para el alumno será más positivo ver una forma de asociar dos palabras que en principio no sólo no tienen nada en común sino que son presentadas como obstáculos para su aprendizaje de la nueva lengua; tanto el mantel como der Mantel "sirven para cubrir"; asimismo, la palabra alemana die Mappe se utilizaba para hacer referencia a la carpeta que guardaba el mapa. Este procedimiento contribuiría a estrechar las distancias entre el léxico alemán y el español.

En este sentido, estas interferencias se reducirían si se cambia el punto de vista sobre los "falsos amigos", en tanto que se resaltarían las semejanzas frente a las diferencias. 


\section{LOS DISTINTOS GRADOS DE SIMILITUD EN "LOS VERDADEROS AMIGOS". CONCLUSIONES}

De los datos obtenidos en el estudio contrastivo de palabras alemanas y palabras españolas mediante la etimología podemos extraer aspectos relativos al grado de similitud entre ellas:

Por un lado, hemos advertido la presencia de "palabras alemanas transparentes”. Se trata de aquellos términos en los que las diferencias gráficas o fonéticas entre las lenguas son mínimas y por ello resulta muy simple establecer la asociación entre las palabras españolas y las palabras alemanas. Algunos ejemplos de “cognados transparentes" son al. Tee > esp. té; al. Marmelade > esp. mermelada; al. Tomate > esp. Tomate.

Por otro lado, hemos definido otro grupo con el nombre de "palabras alemanas translúcidas" bajo el que se incluyen aquellas palabras que, aun procediendo de un mismo origen, no se identifican a simple vista por la evolución gráfica y fonética a lo largo de la historia de la lengua. Las palabras al. Wein > esp. Vino; al. Zitrone > esp. cítrico; al. Öl > óleo, oliva constituyen algunos ejemplos de "cognados translúcidos". Asimismo habría que hacer una diferencia entre Wein y $\mathrm{Zi}$ trone y Öl, pues en las dos últimas palabras el significado no es el real sino que actúan como vínculos para llegar al verdadero significado; esto es, el alumno puede realizar una transferencia entre citrico y limón y entre óleo y aceite por los semas que comparten.

Otra conclusión significativa que hemos podido sacar de nuestra comparación han sido determinadas sistematizaciones sobre las divergencias regulares derivadas del análisis empírico. ${ }^{20}$

Aquí ofrecemos sólo algunos ejemplos ilustrativos que afectan principalmente al campo semántico analizado:

- Cambios en las consonantes oclusivas. Con frecuencia surgen correspondencias entre las consonantes oclusivas de las palabras alemanas y de las españolas. La flecha en las dos direcciones significa que, por ejemplo, allí donde la palabra alemana presenta una $\langle\mathbf{b}\rangle$, la palabra española con la que se asocia lo hace con $\langle\mathbf{p}\rangle$, o viceversa.

20 Se trata, en cierto modo, de continuar con la aportación de G. Wotjak, que él mismo califica de incompleta. Siguiendo con las apreciaciones de este autor sobre dichas correspondencias, por un lado, insiste en que las observaciones que él presenta entre "grafemas y fonemas del español y el alemán no deben utilizarse como recomendaciones fidedignas para la transposición, ya que se requerirían análisis mucho más detallados" (Wotjak: 327). Sin embargo, y volviendo a una de sus citas expuestas en este estudio, esa labor más detallada la entiende como una investigación abordada desde la etimología. Parece ser que, a través de la información etimológica sí sería legítimo presentar estas sistematizaciones como "tendencias o recomendaciones" en la adquisición de lenguas extranjeras (cita en la página 6 de este artículo) 
Este grupo de correspondencias resume, en general, la explicación de muchas asociaciones que se van a citar a lo largo de este apartado:

CONSONANTES OCLUSIVAS

$$
\begin{array}{ll}
\mathrm{b} \leftrightarrow \mathrm{p} & \mathrm{b}, \mathrm{p} \leftrightarrow \mathrm{f} \\
\mathrm{d} \leftrightarrow \mathrm{t} & \mathrm{d}, \mathrm{t} \leftrightarrow \mathrm{z}[\theta] \\
\mathrm{g} \leftrightarrow \mathrm{k} & \mathrm{g}, \mathrm{k} \leftrightarrow \mathrm{ch}, \mathrm{h}[\mathrm{x}]
\end{array}
$$

*las formas con asteriscos serían reconstrucciones ficticias que ayudarían a realizar la transferencia de palabras.

$$
\mathrm{b} \leftrightarrow \mathrm{p}
$$

\begin{tabular}{|l|l|}
\hline al. b & esp.p \\
\hline $\begin{array}{l}\text { Birne } \\
\text { birne }>\text { *pirne }\end{array}$ & pera \\
\hline
\end{tabular}

- En determinadas ocasiones $\mathrm{la}<\mathrm{b}\rangle$ en su combinación con una líquida, a saber $\langle\mathrm{bl}\rangle \mathrm{o}\langle\mathrm{br}\rangle$, se corresponde en español con una $\langle\mathrm{f}\rangle$. Vamos a presentar más ejemplos aunque no sean referidos al campo de la alimentación para que éste no constituya un caso aislado.

\begin{tabular}{|l|l|}
\multicolumn{2}{|c}{$\mathrm{b}, \mathrm{p} \leftrightarrow \mathrm{f}$} \\
\hline al. br & esp. $\mathrm{f}$ \\
\hline braten $>$ *faten & freir \\
\hline Bruder $>$ *fruder & fraterno \\
\hline brechen $>$ *frechen & fractura \\
\hline
\end{tabular}

- Se puede establecer un paralelismo entre muchas palabras alemanas que comienzan por $\langle\mathbf{g}>$ y otras muchas españolas, con las que se asocian, que lo hacen con $\langle\mathbf{h}\rangle$. En estos casos las palabras alemanas suelen conservar la $\langle\mathrm{g}\rangle$ del indoeuropeo mientras las españolas hacen la realización gráfica en $\langle\mathrm{h}\rangle$. Aunque no son ejemplos representativos de la alimentación hemos tomado algunos de nuestro trabajo de más de tres mil palabras para ilustrar esta sistematización.

$$
\mathrm{g}, \mathrm{k} \leftrightarrow \mathrm{ch}, \mathrm{h}[\mathrm{x}]
$$

\begin{tabular}{|l|l|l|}
\hline $\begin{array}{l}\text { Garten } \\
\text { Biergarten }\end{array}$ & $\begin{array}{l}\text { < idg. ghorto-s < idg. } \\
\text { gher- } \\
\text { Garten }>\text { *harten }\end{array}$ & jardín, huerto, cohorte, \\
\hline
\end{tabular}




\begin{tabular}{|l|l|l|}
\hline $\begin{array}{l}\text { Gast } \\
\text { Gasthaus }\end{array}$ & $\begin{array}{l}\text { < idg. ghosti-s } \\
\text { Gast > "hast }\end{array}$ & $\begin{array}{l}\text { hueste, hostil, hostal, hotel, hospi- } \\
\text { tal, hospicio, huésped }\end{array}$ \\
\hline
\end{tabular}

- En otras ocasiones también se evidencia el cambio a la inversa, es decir, $\mathrm{de}\langle\mathrm{k}\rangle \mathrm{a}\langle\mathrm{g}\rangle \mathrm{o} \mathrm{a}\langle\mathrm{h}\rangle$ (Ver cuadro superior de consonantes oclusivas).

\begin{tabular}{|l|l|l|}
\hline kalt & $\begin{array}{l}\text { < idg. gel- "abkühlen, (ge) } \\
\text { frieren" } \\
\text { kalt }>\text { *halt }\end{array}$ & $\begin{array}{l}\text { helar, gelatina, gel, ja- } \\
\text { lea, hielo, } \text { gélido, gla- } \\
\text { cial, glasé }\end{array}$ \\
\hline $\begin{array}{l}\text { das Kind es/ } \\
\text { er }\end{array}$ & $\begin{array}{l}\text { < idg. gen(e)-(educar, } \\
\text { comportarse) } \\
\text { esp. genética < gr. gennetikós < } \\
\text { idg. gen(e) } \\
\text { gr. genéticos < idg. gen(e) } \\
\text { Kind > *Gind }\end{array}$ & $\begin{array}{l}\text { genética, género, genio, } \\
\text { genial, ingenio, her- } \\
\text { mano, progenitor, nacer, } \\
\text { nativo }\end{array}$ \\
\hline das Knie s/- & $\begin{array}{l}\text { <idg. genu- } \\
\text { esp. genuflexión < lat. tardío } \\
\text { genuflexio, -ōnis < idg. genu } \\
\text { esp. genuino (legítimo, cuyo sig- } \\
\text { nificado procede prob. del rito } \\
\text { que efectuaba el padre romano } \\
\text { al reconocer a un hijo suyo : lo } \\
\text { levantaba del suelo y lo colocaba } \\
\text { sobre sus rodillas) } \\
\text { Knie > *Gnie }\end{array}$ & \\
\hline
\end{tabular}

- Se ha observado como de una raíz indoeuropea que contenía la $\langle$ d $>$ ha resultado una palabra en alemán con $\langle s\rangle$. Esta relación se justifica porque las consonantes oclusivas dentales en contacto con una silbante como la $<\mathrm{s}>$ tienden a desaparecer. Veáse como messen, essen y Gemüse derivan de una raíz indoeuropea que contenía una $\langle\mathrm{d}\rangle$, grafema que se ha conservado en las palabras españolas medir, comida y húmedo. También en español hay palabras que han experimentado la misma evolución fonética que las palabras alemanas, a saber, mesura o bumus, en las que la $<\mathrm{d}>$ original del indoeuropeo también ha desaparecido.

\begin{tabular}{|l|l|l|}
\hline essen & $\begin{array}{l}\text { idg. ed- "kauen, essen" } \\
\text { essen > *den }\end{array}$ & $\begin{array}{l}\text { comida, } \\
\text { comedor }\end{array}$ \\
\hline
\end{tabular}




\begin{tabular}{|l|l|l|}
\hline Gemüse & $\begin{array}{l}\text { Colectivo < 'Mus' ("Brei, Speiße”) } \\
\text { Mus < Mast < mad- "jugoso de hume- } \\
\text { dad o de grasa" } \\
\text { Gemüse > *gemüde }\end{array}$ & $\begin{array}{l}\text { húmedo } \\
\text { humus }\end{array}$ \\
\end{tabular}

- Asimismo la $<c>$ en alemán es un signo de préstamo o extranjerismo. Se trata normalmente de palabras, en su mayoría, de origen clásico, procedencia que comparten igualmente muchas palabras alemanas que contienen $\langle\mathrm{k}\rangle \mathrm{O}\langle\mathrm{ch}\rangle$.

\begin{tabular}{|l|l|l|}
\hline Café & $<$ fr. café. & $\begin{array}{l}\text { café } \\
\text { cafetería }\end{array}$ \\
\hline der Chef & $\begin{array}{l}<\text { fr. chef, lat. } \\
\text { caput }\end{array}$ & $\begin{array}{l}\text { chef } \\
\text { jefe }\end{array}$ \\
\hline
\end{tabular}

A partir del balance obtenido en nuestro corpus, consideramos que en líneas generales bajo la denominación de cognados "transparentes" se incluirían la gran mayoría de los préstamos de origen clásico y/o románico en alemán además de los préstamos alemanes o germanos en español y viceversa. Los "cognados translúcidos" comprenderían todas aquellas palabras alemanas cuya asociación con las palabras españolas se establece partiendo de una raíz indoeuropea.

\section{6. $A N E X O$}

\begin{tabular}{|l|l|l|l|}
\hline $\begin{array}{l}\text { PALABRA } \\
\text { ALEMANA }\end{array}$ & ETIMOLOGÍA & VÍNCULO & $\begin{array}{l}\text { PALABRA } \\
\text { ESPAÑOLA }\end{array}$ \\
\hline $\begin{array}{l}\text { die Aprikose } \\
-/ \mathrm{n}\end{array}$ & $\begin{array}{l}<\text { lat. coquere y lat. per- } \\
\text { sica < gr. praikokkion < gr. } \\
\text { beríkokkon } \\
\text { esp. albaricoque < ár. hisp. al- } \\
\text { barqúq < gr. Beríkokkon }\end{array}$ & albaricoque & el albaricoque \\
\hline braten & $\begin{array}{l}\text { Relac. bärme < idg. bher- } \\
\text { Relac. lat. fretum } \\
\text { freir }<\text { lat. frigo, -ere. } \\
\text { SUPUESTO: braten > *fraten }\end{array}$ & $\begin{array}{l}\text { freir } \\
\text { frito }\end{array}$ & asar, freir \\
\hline $\begin{array}{l}\text { die Banane } \\
\text { /n }\end{array}$ & $\begin{array}{l}\text { < port. Banana < una lengua } \\
\text { aborigen africana de Guinea } \\
\text { esp. banana < voz del Congo }\end{array}$ & Banana & el plátano \\
\hline
\end{tabular}




\begin{tabular}{|c|c|c|c|}
\hline die Bar -/s & $\begin{array}{l}<\text { ingl. bar (barra) } \\
\text { esp. bar < ingl. Bar }\end{array}$ & Bar & el bar \\
\hline $\begin{array}{l}\text { das Becken } \\
\text { s/- } \\
\text { das } \\
\text { Spülbecken }\end{array}$ & $\begin{array}{l}<\text { lat. baccinum } \\
\text { esp. bacín (recipiente para } \\
\text { contener líquidos u otras co- } \\
\text { sas) < lat. baccinum }\end{array}$ & bacín & $\begin{array}{l}\text { el lavamanos } \\
\text { el fregadero }\end{array}$ \\
\hline beißen & $\begin{array}{l}\text { < idg. bheid- "hauen, spalten" } \\
\text { (golpear, pegar) Grado cero y } \\
\text { forma nasal bhi-n-d > findo } \\
\text { (separar, dividir) > fisura } \\
\text { esp. bis: "dos, partido en dos, } \\
\text { dos veces" < lat. bis, dos veces } \\
\text { < idg. bheid } \\
\text { esp. fisura (división) < lat. } \\
\text { fissūra < idg. bheid < idg. } \\
\text { bhi-n-d }\end{array}$ & bis, fisura & morder \\
\hline das Bier es/e & $\begin{array}{l}<\text { lat. biber < lat. bibere } \\
\text { esp. beber < lat. bibere }\end{array}$ & beber & la cerveza \\
\hline die Birne /n & $\begin{array}{l}<\text { bira }<\text { lat. pira }<\text { lat. pirum } \\
\text { esp. pera }<\text { lat. pirum }\end{array}$ & pera & la pera \\
\hline ein bisschen & $\begin{array}{l}\text { Concretamente "bocado } \\
\text { pequeño". } \\
\text { Muy prob. relacionado con } \\
\text { "beißen" } \\
\text { Ver "beißen" } \\
\text { < idg. bheid- "hauen, spalten" } \\
\text { (golpear, pegar) Grado cero y } \\
\text { forma nasal bhi-n-d > findo } \\
\text { (separar, dividir)> fisura } \\
\text { esp. bis: "dos, partido en dos, } \\
\text { dos veces" < lat. bis, dos veces } \\
<\text { idg. bheid } \\
\text { esp. fisura (división) < lat. } \\
\text { fissūra < idg. bheid < idg. } \\
\text { bhi-n- }\end{array}$ & $\begin{array}{l}\text { bis } \\
\text { fisura }\end{array}$ & $\begin{array}{l}\text { un poco, un } \\
\text { poquito }\end{array}$ \\
\hline $\begin{array}{l}\text { der Bonbon } \\
\mathrm{s} / \mathrm{s}\end{array}$ & $\begin{array}{l}<\text { fr. Bonbon } \\
\text { esp. bombón < fr. Bonbon }\end{array}$ & $\begin{array}{l}\text { bombón } \\
\text { falso amigo } \\
\text { bombón: al. } \\
\text { die praliné }\end{array}$ & el caramelo \\
\hline
\end{tabular}




\begin{tabular}{|c|c|c|c|}
\hline $\begin{array}{l}\text { brennen } \\
\text { verbrennen } \\
\mathrm{a}-\mathrm{a}\end{array}$ & $\begin{array}{l}\text { Su raíz se relaciona con la eti- } \\
\text { mología de bärme } \\
\text { < idg. bher(e)- (brotar) } \\
\text { esp. hervir < lat. fervēre < idg. } \\
\text { bher- } \\
\text { esp. fermento < lat. fermen- } \\
\text { tum < idg. bher } \\
\text { esp. brandy (originariamente } \\
\text { "vino quemado") < ingl. < } \\
\text { neerl. brandewijn }\end{array}$ & $\begin{array}{l}\text { hervir } \\
\text { fermento } \\
\text { brandy }\end{array}$ & $\begin{array}{l}\text { arder, estar en- } \\
\text { cendido (luz) } \\
\text { quemar }\end{array}$ \\
\hline das Brot es/e & $\begin{array}{l}\text { Relac. bramen > relac. bärme } \\
<\text { idg. bher }(\mathrm{e})-, \text { < bhreu- her- } \\
\text { vir, quemar > lat. fermentum > } \\
\text { fermento } \\
\text { esp. brotar < brotar < gót. } \\
\text { brŭt; cfr. a. al. ant. broz< } \\
\text { brot|zeln: brutzeln > brodeln } \\
<\text { idg. bher- }\end{array}$ & $\begin{array}{l}\text { brotar (el pan } \\
\text { en el momento } \\
\text { de fermentar } \\
\text { parece como } \\
\text { si estuviese } \\
\text { brotando) }\end{array}$ & el pan \\
\hline das Buffet & $\begin{array}{l}<\text { fr. buffet } \\
\text { esp. bufé < fr. buffet }\end{array}$ & bufé & el bufé \\
\hline die Butter & $\begin{array}{l}\text { < lat. butyrum < gr. boútyron } \\
\text { esp. butano < butyrum > bu- } \\
\text { tírico (ácido formado al fer- } \\
\text { mentar la mantequilla rancia) } \\
\text { esp. butiro (mantequilla obte- } \\
\text { nida de la leche batida); } \\
\text { esp. butiroso (mantecoso) < } \\
\text { lat. butyrum, y este del gr. } \\
\text { Boúturon }\end{array}$ & $\begin{array}{l}\text { butano } \\
\text { butiro } \\
\text { butiroso }\end{array}$ & la mantequilla \\
\hline das Café s/s & $\begin{array}{l}\text { < fr. café. } \\
\text { Kaffee < fr. café, it. caffè < } \\
\text { turc. kahve }<\text { arab. qahwa } \\
\text { esp. café, cafetería }<\text { it. caffe }< \\
\text { turc. kahve }<\text { ár. clás. qahwah }\end{array}$ & $\begin{array}{l}\text { café } \\
\text { cafetería }\end{array}$ & $\overline{\text { el café }}$ \\
\hline der Chef s/s & $\begin{array}{l}<\text { fr. chef, lat. caput } \\
\text { esp. jefe }<\text { fr. chef }\end{array}$ & $\begin{array}{l}\text { chef } \\
\text { jefe }\end{array}$ & el jefe / patrono \\
\hline
\end{tabular}




\begin{tabular}{|c|c|c|c|}
\hline der Durst es & $\begin{array}{l}\text { dürr < idg. ters- secar } \\
\text { esp. tierra, territorio, terraplén } \\
<\text { lat. terra (la seca) } \\
\text { esp. tórrido < lat. torridus < } \\
\text { idg. ters- secar } \\
\text { esp. tostar < lat. tostāre < lat. } \\
\text { torridus < idg. ters- secar }\end{array}$ & $\begin{array}{l}\text { tierra, terri- } \\
\text { torio, soterrar, } \\
\text { terraplén, tó- } \\
\text { rrido, tostar }\end{array}$ & la sed \\
\hline $\begin{array}{l}\text { das Dutzend } \\
\text { s/e }\end{array}$ & $\begin{array}{l}<\text { fr. dozeine }<\text { doze }<\text { lat. } \\
\text { duodecim } \\
\text { esp. docena < doce }<\text { lat. } \\
\text { duodĕcim }\end{array}$ & docena & la docena \\
\hline $\begin{array}{l}\text { das Feuer s/- } \\
\text { das } \\
\text { Feuerzeug } \\
\text { die } \\
\text { Feuerwehr }\end{array}$ & $\begin{array}{l}\text { < relac. con gr. pyr < idg. } \\
\text { peuōr, pūr } \\
\text { esp. pirómano < gr. Pyr }\end{array}$ & pirómano & $\begin{array}{l}\text { fuego } \\
\text { el mechero } \\
\text { el cuerpo de } \\
\text { bomberos }\end{array}$ \\
\hline der Fisch & $\begin{array}{l}<\text { lat. piscis } \\
\text { esp. piscis < lat. piscis }\end{array}$ & piscis & pescado \\
\hline $\begin{array}{l}\text { frieren } \\
\text { frisch } \\
\text { gefrieren }\end{array}$ & $\begin{array}{l}\text { < idg. preus- (helarse, arder) } \\
\text { esp. pruina: helarse de frío, } \\
\text { escarcha } \\
\text { esp. fresco < germ. frĭsk, } \\
\text { nuevo, ágil }\end{array}$ & fresco & $\begin{array}{l}\text { tener o pasar } \\
\text { frío, fresco } \\
\text { helarse, } \\
\text { congelarse } \\
\end{array}$ \\
\hline 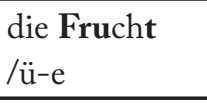 & $\begin{array}{l}<\text { lat. fructus } \\
\text { esp. fruto }<\text { lat. fructus }\end{array}$ & fruto, fruta & la fruta \\
\hline füttern & $\begin{array}{l}<\text { idg. pa(t)- } \\
\text { pāscō, pāstor, pānis } \\
\text { esp. pacer }<\text { lat. pascĕre < lat. } \\
\text { pāscō }<\text { idg. pa(t) } \\
\text { esp. pasto }<\text { lat. pastus < lat. } \\
\text { pāscō }<\text { idg. pa(t) } \\
\text { esp. pan }<\text { lat. panis < lat. } \\
\text { pāscō }<\text { idg. pa(t) } \\
\text { esp. compaña }<\text { (lat. acción } \\
\text { de comer de un mismo pan - } \\
\text { prep. cum-) < lat. panis < lat. } \\
\text { pāscō }<\text { idg. pa(t) }\end{array}$ & $\begin{array}{l}\text { pacer, pasto, } \\
\text { pan, compaña, } \\
\text { compañía, }\end{array}$ & $\begin{array}{l}\text { dar de comer, } \\
\text { echar de comer }\end{array}$ \\
\hline
\end{tabular}




\begin{tabular}{|l|l|l|l|}
\hline die Gabel /n & $\begin{array}{l}\text { <'Giebel'. Originariamente } \\
\text { "Astgabel” que significaba } \\
\text { "asta doblada" y servía como } \\
\text { utensilio para la agricultura. } \\
\text { Giebel < idg. ghebh-(e)1. } \\
\text { esp. gablete (Remate for- } \\
\text { mado por dos líneas rectas y } \\
\text { ápice agudo, que se ponía en } \\
\text { los edificios de estilo ojival) } \\
\text { fr. gablet < lat. gabalus < idg. } \\
\text { ghebh-(e)l. }\end{array}$ & & el tenedor \\
\hline das Gemüse \\
s/-
\end{tabular}




\begin{tabular}{|c|c|c|c|}
\hline $\begin{array}{l}\text { der Imbiss } \\
\text { es, e }\end{array}$ & $\begin{array}{l}\text { <eißen < idg. bheid- (gol- } \\
\text { pear, pegar) Grado cero y } \\
\text { forma nasal bhi-n-d > findo } \\
\text { (separar, dividir)> fisura } \\
\text { esp. bis: "dos, partido en dos, } \\
\text { dos veces" < lat. bis, dos veces } \\
<\text { idg. bheid- } \\
\text { esp. fisura (división) < lat. } \\
\text { fissūra < idg. bheid < idg. } \\
\text { bhi-n-d }\end{array}$ & $\begin{array}{l}\text { bis } \\
\text { fisura }\end{array}$ & $\begin{array}{l}\text { merienda, } \\
\text { refrigerio }\end{array}$ \\
\hline $\begin{array}{l}\text { der Kaffee s } \\
\text { die Kaffee- } \\
\text { machine }\end{array}$ & $\begin{array}{l}<\text { fr. café }<\text { it. caffè }<\text { türk. } \\
\text { kahve < arab. qahwa } \\
\text { esp. café }<\text { it. Caffe }<\text { turco } \\
\text { kahve }<\text { ár. clás. Qahwah }\end{array}$ & café & $\begin{array}{l}\text { el café } \\
\text { la máquina de } \\
\text { café }\end{array}$ \\
\hline der Kakao s & $\begin{array}{l}\text { < esp. cacao < aztek. cacauatl } \\
\text { esp. cacao < nahua cacáhuatl }\end{array}$ & cacao & $\begin{array}{l}\text { el cacao, el } \\
\text { chocolate }\end{array}$ \\
\hline $\begin{array}{l}\text { kalt } \\
\text { die Kälte } \\
\text { sich erkälten } \\
\text { die } \\
\text { Erkältung }\end{array}$ & $\begin{array}{l}\text { < idg. gel- (refrescar, enfriar) } \\
\text { esp. helar < lat. gelāre < lat. } \\
\text { gelū < idg. gel- } \\
\text { esp. gelatina < lat. gelātus < } \\
\text { lat. gelū < idg. gel- } \\
\text { esp. gélido < lat. gelīdus < lat. } \\
\text { gelū < idg. gel- } \\
\text { esp. glacial < lat. glaciālis < lat. } \\
\text { gelū < idg. gel- } \\
\text { esp. glasé < fr. glacé < lat. Gelū } \\
<\text { idg. gel- }\end{array}$ & $\begin{array}{l}\text { helar, gela- } \\
\text { tina, gel, jalea, } \\
\text { hielo, gélido, } \\
\text { glacial, glasé }\end{array}$ & $\begin{array}{l}\text { frío } \\
\text { el frío } \\
\text { coger } \\
\text { el resfriado }\end{array}$ \\
\hline $\begin{array}{l}\text { die Karotte } \\
-/ n\end{array}$ & $\begin{array}{l}<\text { fr. carotte < lat. carota } \\
\text { esp. caroteno (cada uno de } \\
\text { los hidrocarburos no satura- } \\
\text { dos, de origen vegetal y color } \\
\text { rojo, anaranjado o amari- } \\
\text { 1lo. Se encuentran en el to- } \\
\text { mate, la zanahoria, la yema de } \\
\text { huevo, etc., y en los animales } \\
\text { se transforman en las vitami- } \\
\text { nas A.) < lat. carota }\end{array}$ & caroteno & la zanahoria \\
\hline $\begin{array}{l}\text { die Karto- } \\
\text { ffel } / \mathrm{n}\end{array}$ & $\begin{array}{l}<\text { it. tartufo, tartufolo < lat. te- } \\
\text { rrae tuber } \\
\text { esp. tubérculo < tubercŭlum, } \\
\text { dim. de tuber }\end{array}$ & tubérculo & la patata \\
\hline
\end{tabular}




\begin{tabular}{|c|c|c|c|}
\hline der Käse s/- & $\begin{array}{l}<\text { lat. caseus } \\
\text { esp. queso < lat. casĕus }\end{array}$ & queso & el queso \\
\hline der Ketchup & $\begin{array}{l}<\text { ingl. ketchup < chino k'ē } \\
\text { chap } \\
\text { esp. ketchup < ingl. ketchup < } \\
\text { chino k'ē chap }\end{array}$ & ketchup & el ketchup \\
\hline $\begin{array}{l}\text { das } \\
\text { Kilo(gramm) } \\
\text { s/- } \\
\text { der/das Ki- } \\
\text { lometer s/- }\end{array}$ & $\begin{array}{l}\text { fr. kilogramme < gr. chílioi } \\
\text { + fr. gramme < lat. gramma, } \\
\text { gr. grámma } \\
\text { esp. kilogramo, kilómetro < gr. } \\
\text { jílio < idg. ger- }\end{array}$ & $\begin{array}{l}\text { kilogramo } \\
\text { kilómetro }\end{array}$ & $\begin{array}{l}\text { el kilogramo } \\
\text { el kilómetro }\end{array}$ \\
\hline $\begin{array}{l}\text { die Kirs- } \\
\text { che /n }\end{array}$ & $\begin{array}{l}\text { < lat. ceresia < lat. cerasus < gr. } \\
\text { kérasos } \\
\text { esp. cereza < lat. ceresı̆a < lat. } \\
\text { cerasŭum < gr. kepásion }\end{array}$ & Cereza & la cereza \\
\hline kochen & $\begin{array}{l}<\text { lat. coquere (lat. cocere) } \\
\text { esp. cocer < lat. coquĕre } \\
\text { esp. cocinar < lat. coquināre }\end{array}$ & cocer, cocinar & Cocer, cocinar \\
\hline die Küche /n & $\begin{array}{l}<\text { lat. coquina (lat. cocina) }< \\
\text { coquere } \\
\text { esp. cocina }<\text { coquīna }< \\
\text { coquěre }\end{array}$ & Cocina & la cocina \\
\hline $\begin{array}{l}\text { der Kuchen } \\
\text { s/- }\end{array}$ & $\begin{array}{l}\text { < germ. koka, kaka-. Prob. te- } \\
\text { nía relación con el balbuceo } \\
\text { de un bebe como 'Mama' und } \\
\text { 'Papa'. } \\
\text { esp. coca < cat. coca < germ. } \\
\text { koka }\end{array}$ & Coca & el pastel \\
\hline kühl & $\begin{array}{l}<\text { kalt } \\
\text { Kalt < idg. gel- (helar) } \\
\text { esp. helar, hielo < lat. gelāre < } \\
\text { lat. gelū < idg. gel- } \\
\text { esp. gelatina < lat. gelātus < } \\
\text { lat. gelū < idg. gel- } \\
\text { esp. gélido < lat. gelĭdus < lat. } \\
\text { gelū < idg. gel- } \\
\text { esp. glacial, glasé < lat. glaciālis } \\
<\text { lat. gelū < idg. gel- }\end{array}$ & $\begin{array}{l}\text { helar, gelatina, } \\
\text { hielo, gélido, } \\
\text { glacis, glacial, }\end{array}$ & fresco \\
\hline lecker & $\begin{array}{l}<\text { lecken < idg. }{ }^{*}(\mathrm{~s}) \text { leigh- } \\
\text { lat. lingere }>\text { lingo }>\text { lingua }\end{array}$ & lengua & rico, sabroso \\
\hline
\end{tabular}




\begin{tabular}{|c|c|c|c|}
\hline der Likör & $\begin{array}{l}<\text { fr. liqueur < lat. liquor } \\
\text { esp. licor < lat. liqŭor }\end{array}$ & licor & el licor \\
\hline $\begin{array}{l}\text { das/ der Li- } \\
\text { ter s/- }\end{array}$ & $\begin{array}{l}<\text { fr. litre }<\text { fr. litron }<\text { lat. litra } \\
<\text { gr. lítra } \\
\text { esp. litro < fr. litre }\end{array}$ & litro & el litro \\
\hline der Löffel s/- & $\begin{array}{l}<\text { idg. } \operatorname{lab}(\mathrm{h})-, \operatorname{lap}(\mathrm{h})-(\text { lamer }) \\
\text { esp. lamer < lat. lambere (la- } \\
\text { mer })<\text { idg. lab(h)-, lap(h) }\end{array}$ & lamer & la cuchara \\
\hline $\begin{array}{l}\text { die } \mathbf{M a}^{-} \\
\text {jonäse }-/ \mathrm{n}\end{array}$ & $\begin{array}{l}<\text { fr. mayonnaise } \\
\text { esp. mayonesa }<\text { fr. } \\
\text { mayonnaise }\end{array}$ & mayonesa & la mayonesa \\
\hline $\begin{array}{l}\text { der Man- } \\
\text { tel s/ä }\end{array}$ & $\begin{array}{l}<\text { lat. Mantellum } \\
\text { esp. mantel < lat. mantēle < } \\
\text { lat. mantellum }\end{array}$ & $\begin{array}{l}\text { mantel } \\
\text { falso amigo } \\
\text { mantel: al. } \\
\text { tischtuch }\end{array}$ & $\begin{array}{l}\text { el abrigo; la } \\
\text { gabardina }\end{array}$ \\
\hline $\begin{array}{l}\text { der Markt } \\
\text { es/ä-e }\end{array}$ & $\begin{array}{l}<\text { lat. mercatus } \\
\text { esp. mercado < lat. mercātus }\end{array}$ & mercado & el mercado \\
\hline $\begin{array}{l}\text { die } \\
\text { Marmelade }\end{array}$ & $\begin{array}{l}<\text { port. marmelada }<\text { lat. meli- } \\
\text { melum }<\text { gr. melimēlon } \\
\text { esp. mermelada }<\text { port. } \\
\text { marmelada }\end{array}$ & mermelada & la mermelada \\
\hline das Mehl s/e & $\begin{array}{l}\text { Mehl < maleen } \\
<\text { idg. (s)mel- < idg. mel- } \\
\text { esp. molino, molinero < lat. } \\
\text { molīnum }\end{array}$ & $\begin{array}{l}\text { molino, } \\
\text { molinero }\end{array}$ & la harina \\
\hline $\begin{array}{l}\text { das Menü } \\
\text { s/s }\end{array}$ & $\begin{array}{l}<\text { fr. menu (originariamente } \\
\text { significaba pequeño) < lat. } \\
\text { minuere } \\
\text { esp. menu < fr. menu }\end{array}$ & menú & el menú \\
\hline die Milch & $\begin{array}{l}<\text { 'melken' < idg. mel(e)g } \\
\text { "melken" } \\
\text { esp. emulsión < lat. emulsus } \\
<\text { lat. mulgeō < idg. mel (e)g } \\
\text { "melken" } \\
\text { esp. emulsivo < lat. emulsus } \\
<\text { lat. mulgeo < idg. mel(e)g } \\
\text { "melken" }\end{array}$ & $\begin{array}{l}\text { emulsión, } \\
\text { emulsivo }\end{array}$ & la leche \\
\hline
\end{tabular}




\begin{tabular}{|c|c|c|c|}
\hline mild & $\begin{array}{l}<\text { mahlen < idg. }(\text { s)mel- } \\
\text { esp. molido < moler < lat. } \\
\text { molo < idg. (s)mel }\end{array}$ & molido & $\begin{array}{l}\text { dulce, tierno, } \\
\text { suave }\end{array}$ \\
\hline mischen & $\begin{array}{l}\text { < lat. miscere } \\
\text { esp. mezclar < lat. vulg. } \\
\text { misculāre } \\
\text { esp. miscible < lat. miscibı̆lis < } \\
\text { adj. verbal de miscēre } \\
\text { esp. mixto < lat. mixtus < lat. } \\
\text { miscēre }\end{array}$ & $\begin{array}{l}\text { mezclar, mis- } \\
\text { cible, mestizo, } \\
\text { mixto }\end{array}$ & mezclar \\
\hline das Mü(e)sli & & musli & musli \\
\hline $\begin{array}{l}\text { die Nuss -/ } \\
\text { Nüsse }\end{array}$ & $\begin{array}{l}<\text { lat. nux } \\
\text { esp. nuez < lat. nux }\end{array}$ & la nuez & la nuez \\
\hline das Ö1 s/e & $\begin{array}{l}<\text { lat. oleum < gr. élaion } \\
\text { esp. oliva, olivo < lat. olīvum < } \\
\text { lat. oleum } \\
\text { esp. oleo < lat. olīvum < lat. } \\
\text { oleum }\end{array}$ & $\begin{array}{l}\text { óleo, oliva, } \\
\text { olivo }\end{array}$ & $\begin{array}{l}\text { el aceite; el pe- } \\
\text { tróleo; el óleo }\end{array}$ \\
\hline die Pizza -/s & $\begin{array}{l}\text { < it. Pizza } \\
\text { esp. pizza < it. pizza }\end{array}$ & pizza & la pizza \\
\hline $\begin{array}{l}\text { die Pommes } \\
\text { (frites) }\end{array}$ & $\begin{array}{l}\text { < fr. pomme < lat. pōma, pl. n. } \\
\text { de pōmum } \\
\text { esp. poma < lat. pōma, pl. n. de } \\
\text { pōmum }\end{array}$ & poma manzana & $\begin{array}{l}\text { patatas fritas } \\
\text { también } \\
\text { manzana }\end{array}$ \\
\hline probieren & $\begin{array}{l}<\text { al. probe < lat. proba } \\
\text { esp. probar < lat. proba }\end{array}$ & probar & probar \\
\hline $\begin{array}{l}\text { die Quali- } \\
\text { tät /en }\end{array}$ & $\begin{array}{l}<\text { lat. qualitas < qualis } \\
\text { esp. calidad < lat. qualĭtas }\end{array}$ & calidad & la calidad \\
\hline $\begin{array}{l}\text { die Quanti- } \\
\text { tät /en }\end{array}$ & $\begin{array}{l}<\text { lat. quantitas } \\
\text { esp. cantidad < lat. quantĭtas }\end{array}$ & cantidad & la calidad \\
\hline $\begin{array}{l}\text { das Restau- } \\
\text { rant s/s }\end{array}$ & $\begin{array}{l}\text { fr. restaurant }<\text { restaurer }<\text { lat. } \\
\text { restaurāre } \\
\text { esp. restaurante }<\text { lat. } \\
\text { restaurāre }\end{array}$ & restaurante & el restaurante \\
\hline roh & $\begin{array}{l}\text { < idg. kreu- kreue- cortarse } \\
\text { (vom Blut) } \\
\text { kreud- (carne cruda) } \\
\text { esp. crudo < lat. crudus < idg. } \\
\text { kreu }\end{array}$ & crudo & $\begin{array}{l}\text { crudo; grosero, } \\
\text { bruto }\end{array}$ \\
\hline
\end{tabular}




\begin{tabular}{|c|c|c|c|}
\hline der Saft s/ä & $\begin{array}{l}\text { < idg. sap- } \\
\text { esp. savia < lat. sapĕa, de sapa } \\
<\text { idg. sap- } \\
\text { esp.sabor < lat. sapor < idg. } \\
\text { sap- }\end{array}$ & $\begin{array}{l}\text { savia } \\
\text { sabor }\end{array}$ & el jugo \\
\hline das $\mathbf{S a l} z$ es/e & $\begin{array}{l}<\text { idg. sal- (sal) } \\
\text { esp. sal, salazón, salinidad < } \\
\text { lat. sal < gr. als } \\
\text { esp. salario < lat. salarŭum < sal }\end{array}$ & $\begin{array}{l}\text { sal, salar, sa- } \\
\text { lario, sala- } \\
\text { zón, salina, } \\
\text { salinidad }\end{array}$ & la sal \\
\hline $\begin{array}{l}\text { das Sand- } \\
\text { wich es/e }\end{array}$ & $\begin{array}{l}<\text { ingl. Sandwich } \\
\text { esp. sándwich < ingl. sandwich }\end{array}$ & sándwich & el sándwich \\
\hline satt sein & $\begin{array}{l}<\text { idg. sa-, se- } \\
\text { esp. saciar, saciedad, satisfacer } \\
<\text { lat. satiāre < idg. sa-, se- } \\
\text { esp. saturar < lat. saturāre < } \\
\text { idg. sa-, se- }\end{array}$ & $\begin{array}{l}\text { saciar, sacie- } \\
\text { dad, satisfacer, } \\
\text { saturar }\end{array}$ & estar satisfecho \\
\hline schälen & $\begin{array}{l}<\text { “Schale" < 'Schild' (s)kel- } \\
\text { (cortar, rajar) } \\
\text { esp. cuchillo < lat. cultellus < } \\
\text { idg. (s)kel- } \\
\text { esp. esculpir < lat. sculpĕre < } \\
\text { idg. (s)kel- } \\
\text { esp. escultura < lat. sculptūra < } \\
\text { idg. (s)kel- } \\
\text { esp. escalpelo < lat. scalpellum } \\
<\text { idg. (s)kel- }\end{array}$ & $\begin{array}{l}\text { cuchillo, es- } \\
\text { culpir, escul- } \\
\text { tura (rascar), } \\
\text { escalpelo / } \\
\text { escarpelo }\end{array}$ & pelar \\
\hline $\begin{array}{l}\text { die } \\
\text { Spaguetti }\end{array}$ & $\begin{array}{l}<\text { it. Spaghetti } \\
\text { espaguetis < it. spaghetti }\end{array}$ & espaguetis & espaguetis \\
\hline $\begin{array}{l}\text { die Speise /n } \\
\text { die } \\
\text { Nachspeise }\end{array}$ & $\begin{array}{l}<\text { lat. expensa (pecunia) < ex- } \\
\text { pensum }<\text { expendere expensiv } \\
<\text { ex+pendo } \\
\text { esp. despensa < lat. dispensus } \\
<\text { dis+pendō }\end{array}$ & despensa & $\begin{array}{l}\text { la comida, el } \\
\text { plato } \\
\text { el postre }\end{array}$ \\
\hline $\begin{array}{l}\text { der } \\
\text { Supermarkt }\end{array}$ & $\begin{array}{l}\text { < ingl. supermarket } \\
\text { palabra compuestas super/ } \\
\text { markt } \\
\text { esp. super < lat. super } \\
\text { markt < lat. mercatus } \\
\text { esp. mercado < lat. mercātus }\end{array}$ & supermercado & $\begin{array}{l}\text { el } \\
\text { supermercado }\end{array}$ \\
\hline
\end{tabular}




\begin{tabular}{|c|c|c|c|}
\hline die Suppe /n & $\begin{array}{l}<\text { niederd. suppe }<\text { fr. soupe }< \\
\text { idg. seup } \\
\text { esp. sopa }<\text { germ. * sŭppa }< \\
\text { idg. seup }\end{array}$ & sopa & la sopa \\
\hline süß & $\begin{array}{l}\text { < idg. suad- (dulce, agradable) } \\
\text { esp. suave < lat. suāvis < idg. } \\
\text { suad- } \\
\text { esp. persuadir < lat. persuadēre } \\
<\text { idg. suad- }\end{array}$ & $\begin{array}{l}\text { suave } \\
\text { persuadir }\end{array}$ & dulce \\
\hline die Tasse /n & $\begin{array}{l}<\text { fr. tasse }<\operatorname{arab} . \operatorname{Tas}\left(a^{\mathrm{h}}\right)< \\
\text { pers. Tast } \\
\text { esp. taza }<\text { hiesp. tássa }<\text { tassah } \\
<\text { persa tašt }\end{array}$ & taza & la taza \\
\hline $\begin{array}{l}\text { der Tee s/ } \\
\text { Teesorten }\end{array}$ & $\begin{array}{l}\text { Thee }(<\text { neerl } .)<\text { chino } \\
\text { esp. te }<\text { chino }\end{array}$ & té & el té \\
\hline der Teller s/- & $\begin{array}{l}<\text { lat. taliare }<\text { lat. talea } \\
\text { Originariamente plato donde } \\
\text { se colocaba la carne para ser } \\
\text { cortada } \\
\text { esp. talla }<\text { lat. taliare }\end{array}$ & tallar & el plato \\
\hline $\begin{array}{l}\text { die Tomate } \\
-/ \mathrm{n}\end{array}$ & $\begin{array}{l}<\text { fr. tomate }<\text { esp. tomate }< \\
\text { nahua. tomatl }\end{array}$ & tomate & el tomate \\
\hline $\begin{array}{l}\text { trinken a-u } \\
\text { das Getränk } \\
\text { s/e }\end{array}$ & $\begin{array}{l}\text { esp. trincar (tomar bebidas al- } \\
\text { cohólicas) < al. trinken }\end{array}$ & trincar & $\begin{array}{l}\text { beber } \\
\text { la bebida }\end{array}$ \\
\hline $\begin{array}{l}\text { warm /wär- } \\
\text { mer /am } \\
\text { die Wärme }\end{array}$ & $\begin{array}{l}<\text { idg. uer- (arder, ennegrecer) } \\
\text { esp. terma, termo < gr. } \\
\text { thermós }\end{array}$ & terma, termo & $\begin{array}{l}\text { caliente,cálido } \\
\text { el calor }\end{array}$ \\
\hline $\begin{array}{l}\text { das Was- } \\
\text { ser s/- } \\
\text { das } \\
\text { Trinkwasser }\end{array}$ & $\begin{array}{l}<\text { idg. uédor, uodor- < idg. } \\
\text { aued- (fluir) < wed- (agua, } \\
\text { mojado) } \\
\text { esp. vaselina (agua y aceite; se } \\
\text { trata de una marca registrada } \\
\text { pero conserva el prefijo) }\end{array}$ & vaselina & $\begin{array}{l}\text { el agua } \\
\text { el agua para } \\
\text { beber }\end{array}$ \\
\hline $\begin{array}{l}\text { der Wein } \\
\text { es/e }\end{array}$ & $\begin{array}{l}<\text { lat. vinum } \\
\text { esp. vino < lat. vinum }\end{array}$ & vino & el vino; la vid \\
\hline $\begin{array}{l}\text { die Zitrone } \\
-/ n\end{array}$ & $\begin{array}{l}<\text { it. citrone }<\text { lat.citrus } \\
\text { esp. citrón, cítrico < lat. citrus }\end{array}$ & $\begin{array}{l}\text { citrón } \\
\text { cítrico }\end{array}$ & $\begin{array}{l}\text { el citrón } \\
\text { (limón) } \\
\text { el cítrico }\end{array}$ \\
\hline
\end{tabular}




\begin{tabular}{|l|l|l|l|}
\hline der Zucker & $\begin{array}{l}\text { < it. zucchero < arab. sukkar < } \\
\text { aind. sarkara } \\
\text { esp. azúcar < ár. hiesp. azúcar } \\
\text { < ár. clás. Sukkar < gr. sákxapi }\end{array}$ & el azúcar \\
\hline
\end{tabular}

\section{BIBLIOGRAFÍA}

R. Arntz, Studien zur Sprache und Technik, Hildesheim, Georg Olms Verlag, 2001

R. Boнn, Probleme der Wortschatzarbeit, Kassel, DIFF/Goethe Institut, 2000

N. Cartegena / H.M., Gauger, Vergleichende Grammatik Spanisch-Deutsch. 2 Bände, Mannheim, Dudenverlag, 1989.

J. Casares, Diccionario ideológico de la lengua española. Barcelona, Editorial Gustavo Gil, 1990.

J. Corominas, Breve diccionario etimológico de la lengua castellana, Madrid, Gredos, 2000.

Diccionario de la Lengua Española [Archivo de ordenador]. Madrid, Espasa-Calpe. 22a Edición, 1998.

Duden, deutsches Universalwörterbuch, Mannheim [Etc.] , Dudenverlag, 1996.

Duden, Etymologie, Herkunftswörterbuch der deutschen Sprache, Mannheim [etc.]: Dudenverlag, 1989.

Duden, Vom Deutschen Wort Zum Fremdwort Worterbuch zum richtigen Fremdwortgebrauch. Mannheim: Dudenverlag 2003.

M. Fernández, "La interacción negativa y positiva del inglés en el aprendizaje del alemán como L3: una propuesta de integración", El alemán en su contexto español: actas IV congreso de la Federación de Asociaciones de Germanistas y profesores de Alemán en España, Santiago de Compostela, 26-28 de septiembre de 2002, Publicacións e Intercambio Científico, 2002, pp. 72-78

V. García, Diccionario etimológico español e hispano, Madrid, Espasa-Calpe, 1985.

M. Glaboniat, / M. Müller, Profile Deutsch. Gemeinsamer europäische Referenzrahmen, Berlín, Langenscheidt, 2005.

B. Hufeisen, / G. Neuner, Mehrsprachigskeitskonzept: Tertiärsprachenlernen-Deutsch nach Englisch. Europarat, Goethe Institut, 2003

H. Klein, / T. Stegmann, EuroComRom. Die sieben Siebe. Aachen, Shaker, 1999.

F.H. KLuge, Etymologisches Worterbuch der deutschen Sprache, Berlín, De Gruyter, 1989.

R. Lado, Lingüistica contrastiva. Lenguas y culturas. Traducción de Joseph A. Fernández, Madrid, Ediciones Alcalá, 1957.

M. Lewis, How to study foreign languages, New York, Palgrave, 1999

D. Ludwig, Sprachfallen. Spanisch, München, Max Hueber Verlag, 2001.

K. Маснт, / F. Steiner, Erfolgsfaktoren des Vokabellernens, Augsburg, Universität Augsburg, 1983.

R.M. Manchón, "Un acercamiento psicolingüístico al fenómeno de la transferencia en el aprendizaje y el uso de segundas lenguas", AA.VV. Estudios de Lingüistica. Tendencias y lineas de investigación en adquisición de segundas lenguas. Alicante, Universidad de Alicante, 2001, pp. 37-155. 
J. M. Martín, "Lexicología contrastiva: principios, orientaciones, métodos." en J., Luque, / A., Bertrán, Segundas jornadas sobre estudio y enseñanza del léxico. Granada: Método Ediciones, 1996, pp. 24-27.

R. Pierson, "Using etymology in the classroom", Revista ELT Journal, 43/1 (January, 1989). pp. 143-157

K. RAsк, Von der Etymologie überhaupt? Eine Einleitung in die Sprachvergleichung Tübingen: Gunter Narr, 1992.

J. Rusıескі, "Latent Bilingualism", Revista Papers and Studies in contrastive linguistics, 12 (1980), pp. 82-85.

O. Weller, Polnisch via Russisch verstehen. Slavische Interkomprehension im Rahmen der EuroCom-Strategie. Bielefeld, Universität Bielefeld, 2001

D. WolfF, Fremdsprachenlernen als Konstruktion: Grundlagen für eine konstruktivistische Fremdsprachendidaktik, Frankfurt am Main, Peter Lang, 2002.

G. Wотјак, Las lenguas, ventanas que dan al mundo: el léxico como encrucijada entre morfosintaxis y cognición: aspectos semánticos y pragmáticos en perspectiva intra e interlingüistica, Salamanca, Ediciones Universidad de Salamanca, 2006.

Nombre del autor: Cristina Martínez Fraile

Dirección-e: $\quad$ cmartinez@us.es

Dirección postal: Universidad de Sevilla, Facultad de Filología, Dpto. de Filología Alemana, C/ Palos de la Frontera, s/n, 41004, Sevilla

Fecha de recepción: 26/04/2010

Fechade aceptación: 14/07/2010 